\title{
Structural packaging foams prepared by uni-directional freezing of paper sludge cellulose nanofibres and poly (vinyl alcohol).
}

\author{
Cynthia Adu ${ }^{\mathrm{a}}$, Sameer Rahatekar ${ }^{\mathrm{b}^{*}}$, Jyoti Filby ${ }^{\mathrm{b}}$, David Ayre ${ }^{\mathrm{a}}$, Mark Jolly \\ ${ }^{a}$ Manufacturing and Materials Department, Cranfield University, MK43 OAL, UK \\ ${ }^{b}$ Enhanced Composites and Structures Centre, School of Aerospace, Transport and Manufacturing, Cranfield \\ University, Bedfordshire MK43 OAL, United Kingdom
}

Keywords: Cellulose nanofibres, Aerogel, Foam, Ice-templating

\begin{abstract}
Porous foams from cellulose nanofibres (CNF) and poly-vinyl alcohol CNF/PVA were prepared by uni-directional freezing to create a homogeneous pore structure. The CNF was derived from paper mills sludge (PMS), a by-product of paper manufacturing waste-water treatment. Sodium tetraborate decahydrate (borax) was used as a crosslinking agent. The density of the CNF/PVA foams were $0.03 \mathrm{gcm}^{-3}$ with a compressive strength of $116 \mathrm{kPa}$ at $20 \%$ strain. The foams were competitive to commercial expanded polystyrene (EPS) foam.
\end{abstract}

\section{Introduction}

Polymer foams produced from polyurethane (PU), polystyrene (PS) are rigid, lightweight and energy absorbent desirable for packaging applications. However, these materials largely rely on petroleum crude oil as feedstock, use blowing agents that emit greenhouse gases and leach out microplastics in aquatic habitat. Thereby leading to significant environmental impacts $[1,2]$. Meanwhile, environmental friendly alternatives such as petroleum based bio-polymers; Poly (Vinyl alcohol) PVA and renewable resource based bio-polymers; Poly-lactic Acid (PLA), Polyhydroxyalkanoates (PHAs) have limitations in foam applications due to their low mechanical properties [2,3]. Thus, researchers have employed reinforcement fillers like silica, carbon nanotubes (CNT), cellulose nanofibers (CNF) and graphene to aid their performance [4-6]. Particularly, CNF is an interesting material for reinforcement in foams due to its high aspect ratio, biodegradability, flexibility and crystallinity [7]. However, CNF is limited by agglomeration if used in foam production processes such as compression moulding, injection moulding, extrusion, solvent exchange and spin coating [8]. To improve dispersion and increase the addition of CNF, ice-templating can be used for fabrication of polymer foams. Therefore, this study investigates the use of ice-templating to prepare packaging foams from CNF and PVA to be compared with commercial petroleum based foams. The fundamental process of ice-templating (IT) is based on the growth of ice crystals in a solvent which sublimates, leaving an orderly pore formation in the material [9].

CNF was derived from paper mill sludge (PMS) a by-product of paper mills proven to be a successful source of nanocellulose production due to its reduced processing cost, and no requirement 
for chemical treatment [10]. The CNF and PVA solution was crosslinked with Sodium tetraborate decahydrate and using the uni-directional freezing method. This entails a liquid nitrogen bath $<-180{ }^{\circ} \mathrm{C}$ in an insulated polystyrene vessel, a copper rod used as a localised cold surface allowing the solution to freeze from the bottom up (Fig.1). This freezing method influences the ice growth, pore formation and mechanical properties of the foam [11].

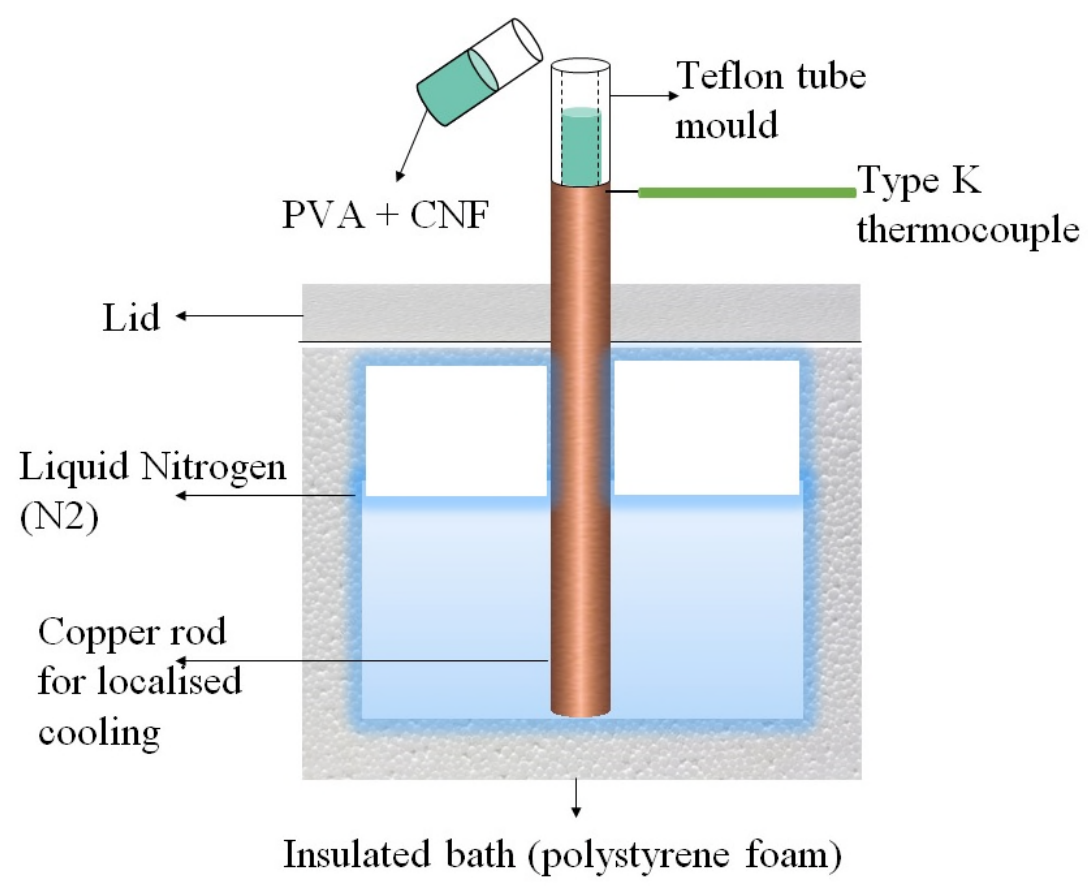

Fig. 1. Experiment set-up for uni-directional freezing.

In the literature, ice-templated PVA foams have been prepared with CNF, chitin nanowhiskers, montmorillonite (MTM) clay, crosslinking agent to enhance the pore structure of foams [12-15]. Unidirectional freezing method has also been used to produce fire retardant phosphorylated-CNF foams [16] and graphene oxide CNF foams [17]. However, uni-direction freezing of CNF/PVA has not been studied, most studies employ fast freeze method by dipping the solution in liquid nitrogen or slow freezing whereby the solution is refrigerated at $-20^{\circ} \mathrm{C}$ for $24 \mathrm{hrs}[15,18]$. Slow freezing hinders the orderly growth of ice crystals as the sample is frozen from all directions which in turn affects the mechanical properties of the foam.

\section{Materials and methods}

\subsection{Materials}

PMS obtained from a UK mill producing kitchen towel rolls was mechanically homogenised using a supermass colloider MKCA6-3 (Masuko Sangyo Co, Japan), details on CNF preparation can be found in our previous study [10]. The CNF had an average width of 50nm, crystallinity index of $43 \%$, chemical composition of $74 \%$ cellulose and $2.6 \%$ hemicellulose. PVA was purchased from Sigma 
Aldrich with MW 89,000-98,000 g/mol, 99+\% hydrolysed. Sodium tetraborate decahydrate (Na2B4O7·10H2O) also known as borax, was purchased from Sigma Aldrich with MW: $381.37 \mathrm{~g} / \mathrm{mol}$.

\subsection{Preparation of CNF/PVA foams}

The PVA solution was prepared by diluting $2 \mathrm{~g}$ of PVA in $100 \mathrm{ml}$ of distilled water ( $2 \mathrm{wt} \%$ ) at $80^{\circ} \mathrm{C}$, vigorously stirred for $4 \mathrm{hrs} .5 \mathrm{mg} / \mathrm{ml}$ of Borax was added to the PVA solution as a crosslinker at. $100 \mathrm{ml} 2 \mathrm{wt} \%$ suspension of CNF was added to the PVA and borax solution and vigorously stirred for $12 \mathrm{hrs}$. Each foam was prepared from a $10 \mathrm{ml}(2 \mathrm{wt} \%$ PVA, $2 \mathrm{wt} \% \mathrm{CNF}$ and $0.5 \mathrm{wt} \%$ borax) solution of 50:50 CNF/PVA using the directional freezing method. Each sample was frozen after 10 mins and placed in a freeze dryer at $-52^{\circ} \mathrm{C}$ and 0.1 pascals.

\subsection{Characterisation of CNF/PVA foams}

Compression test was conducted using an Instron 5500R universal testing machine with $100 \mathrm{~N}$ load cell at $1 \mathrm{~mm} / \mathrm{min}$ crosshead speed in a conditioned environment of $23{ }^{\circ} \mathrm{C}$ and $\mathrm{RH} 51 \%$. After conditioning, the apparent density ( $\rho$ app) of the samples were calculated. Eight cylindrical shaped specimens were tested. Compressive strength was calculated at $10 \%$ strain and compressive modulus calculated from the linear portion of the stress-strain curve. The foams were cut vertically along the direction of freezing and coated with gold particles to observe their pore size using Scanning Electron Microscope (SEM) JSM-6490LV, JEOL (Japan) and measured using imageJ software (USA).

\section{Result and discussion}

\subsection{Morphology}

The foam weighted an average of $0.238 \mathrm{~g}, 25 \mathrm{~mm}$ in diameter and $17.3 \pm 1.4 \mathrm{~mm}$ in height which was used to calculate the apparent density ( $\left.\rho_{\text {app }}\right)$ of $28 \mathrm{~kg} / \mathrm{m}^{3}$. The foam porosity is calculated using the equation ( $\left.1-\rho_{\text {rel }}\right)$ where $\rho_{\text {rel }}$ is the quotient of $\left(\rho_{\text {app }}\right)$ divided by the cell-wall density ( $\rho$ cell $)$ [19]. The cell-wall density is taken as the $50: 50$ ratio of $1500 \mathrm{~kg} / \mathrm{m}^{3}$ for cellulose and $1190 \mathrm{~kg} / \mathrm{m}^{3}$ for PVA. The average porosity of the foams resulted in $97.9 \pm 0.3 \%$. Unidirectional freezing allows the foam to exhibits a lamellar channel structure in the direction of freezing $[11,20]$, this can be observed at a lower magnification in Fig.2c. At higher magnification (Fig 2d) the foam shows cellular pores with honeycomb-like structure with an average pore size of $3.2 \pm 0.9 \mu \mathrm{m}$. The higher aspect ratio of CNF and entanglement affects the orientation of the pores which plays a major role in the morphology of the cell wall and enhances reinforcement of the PVA foam. This effect was explained in an early study of CNF reinforced starch foams [21]. 


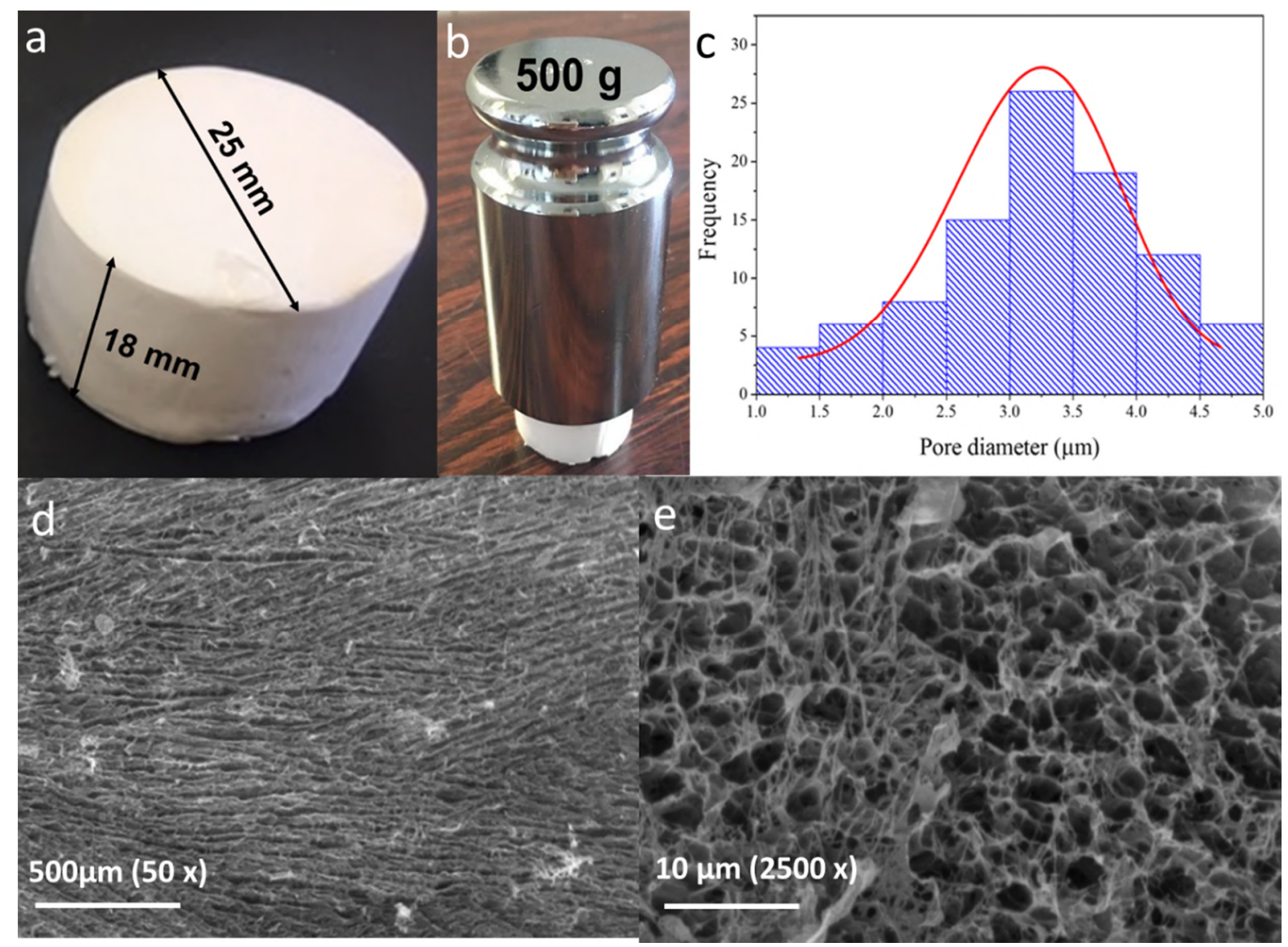

Fig.2. (a) Physical foam sample (b) Foam sample supporting over 2000 times its weight (c) histogram of foam pore size with normal distribution curve (d) SEM scan of foam at 50x magnification (e) $2500 \mathrm{x}$ magnification.

\subsection{Mechanical properties}

The stress-strain curve of the foam (Fig.3a) exhibits a linear-elastic region up to $10 \%$ strain followed by a plateau in stress expected of a rigid polymer foam [22]. The average compressive strength of the foam at $10 \%$ and $20 \%$ strain is $0.082 \mathrm{MPa}(82 \mathrm{kPa})$ and $0.100 \mathrm{MPa}(100 \mathrm{kPa})$ respectively. In (Fig 3b) an Ashby plot of the density vs compressive strength of CNF/PVA foams in the literature prepared by the slow freezing is shown [12,23]. PB-CNF I foam prepared by Han et al., despite being 3 times denser $\left(110 \mathrm{~kg} / \mathrm{m}^{3}\right)$ revealed a compressive strength of $0.150 \mathrm{MPa}$. The CNF/PVA foams in this work show competitive compressive strength at $10 \%$ strain. Hence this implies the influence of the unidirectional freezing method on the foams mechanical properties. 

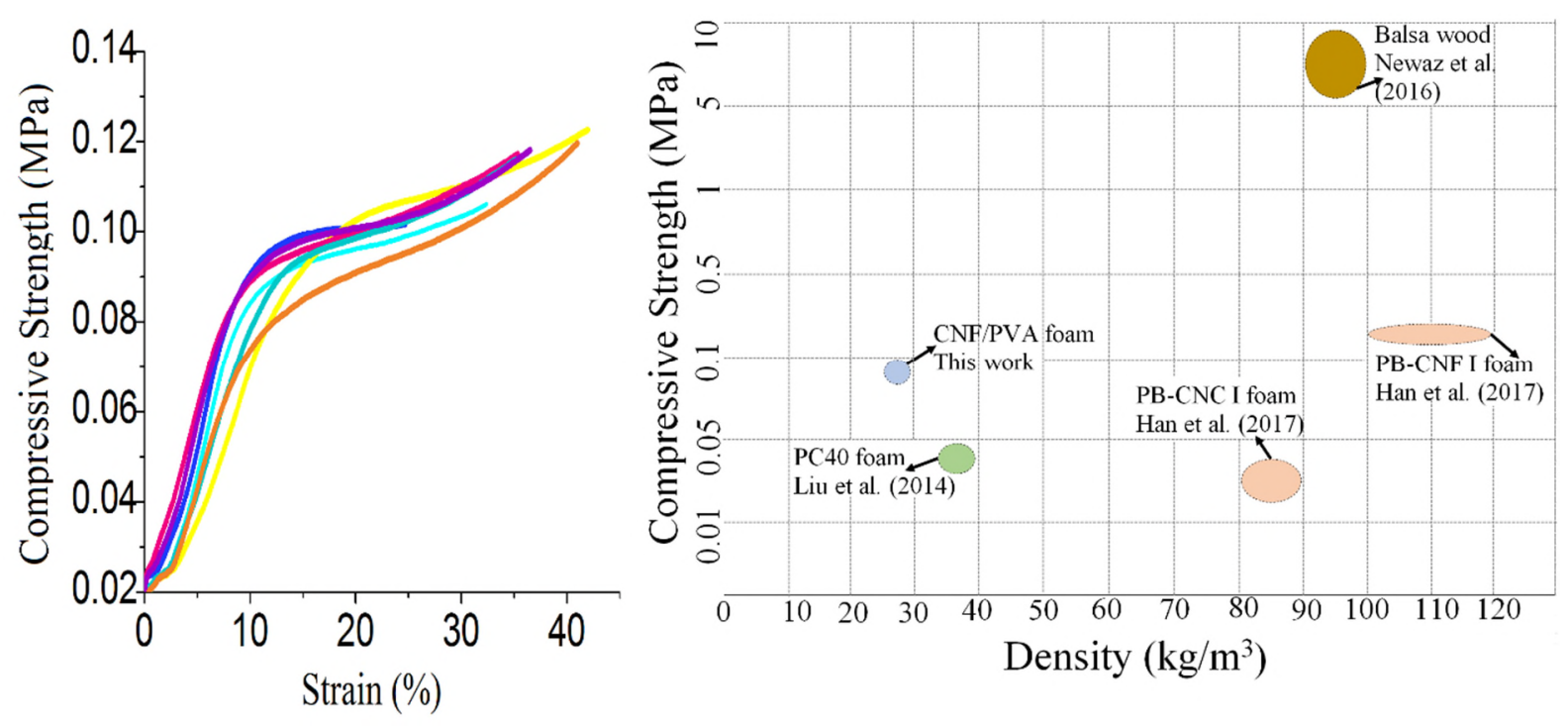

Fig.3. Mechanical properties of CNF/PVA foams (a) Compressive stress-strain curve (b) Density vs compressive strength of foams and balsa wood as reference [24].

The elastic modulus was determined from the slope of the linear portion of the curve resulting in an average of $930 \pm 10 \mathrm{kPa}$. Energy absorption was calculated from the area under the stress-strain curve reaching an average of $3.2 \mathrm{~kJ} / \mathrm{m}^{3}$ at $30 \%$ strain.

\subsection{Comparison with commercial EPS}

The CNF/PVA foam can be classified for high duty in accordance with BS 3837-1:2004 [25]. The CNF/PVA foam was compared with compressive strength data of commercially available foams. Jabfloor EPS100 (Jablite, UK) is expanded polystyrene foam used as floor insulation in offices and schools [26]. Ethafoam ${ }^{\mathrm{TM}} 180$ (Dow Chemicals, USA) is a polyethylene foam used in packaging applications and for cushioning [27].

Table 1. Comparison of CNF/PVA to commercial EPS

\begin{tabular}{|c|c|c|c|c|}
\hline Foam type & Material & $\begin{array}{l}\text { Density } \\
\left(\mathrm{kg} / \mathrm{m}^{3}\right)\end{array}$ & $\begin{array}{l}\text { Compressive strength } \\
\text { @ } 10 \% \text { strain }(\mathrm{kPa})\end{array}$ & $\begin{array}{l}\text { Compressive strength } \\
\text { (a) } 20 \% \text { strain }(\mathrm{kPa})\end{array}$ \\
\hline Jablite EPS 100 & Polystyrene & 20 & 100 & - \\
\hline EthafoamTM & Polyethylene & 29 & 30 & 50 \\
\hline This work & PVA-CNF & $28 \pm 3$ & $82 \pm 7$ & $100 \pm 3$ \\
\hline
\end{tabular}

\section{Conclusions}

Paper mill sludge processed into cellulose nanofibres was crosslinked with polyvinyl alcohol to produce a sustainable polymer foam capable of supporting over 2000 times its weight. The foam is suggested as protective packaging. However, the CNF/PVA foams is prone to water absorption, 
increasing the content of borax in future study could improve moisture absorption. Coating the foam surface with a hydrophobic film or spray may aid reduction in water absorption. Nonetheless, water solubility is an advantage during disposal and decomposition in single-use packaging applications.

\section{Acknowledgement}

This work is funded by the Engineering and Physics Research Science Council (EPSRC) UK and Ecoganix LTD under grant number EP/L016389/1. The CNF preparation was supported by funding from Bio4Energy Swedish strategic research program and Luleå University of Technology, Sweden.

Data underlying this study can be accessed through the Cranfield University repository: https://doi.org/10.17862/cranfield.rd.7993436.v1

https://cord.cranfield.ac.uk/s/647edd258ab42f59e0db 


\section{References}

[1] A. Kylili, L. Seduikyte, P.A. Fokaides, Life Cycle Analysis of Polyurethane Foam Wastes, Elsevier Inc., 2018. doi:10.1016/b978-0-323-51133-9.00009-7.

[2] K. Duis, A. Coors, Microplastics in the aquatic and terrestrial environment: sources (with a specific focus on personal care products), fate and effects, Environ. Sci. Eur. 28 (2016) 1-25. doi:10.1186/s12302-015-0069-y.

[3] M.M. Reddy, S. Vivekanandhan, M. Misra, S.K. Bhatia, A.K. Mohanty, Biobased plastics and bionanocomposites: Current status and future opportunities, Prog. Polym. Sci. 38 (2013) 1653-1689. doi:10.1016/j.progpolymsci.2013.05.006.

[4] P. Bordes, E. Pollet, L. Avérous, Nano-biocomposites: Biodegradable polyester/nanoclay systems, Prog. Polym. Sci. 34 (2009) 125-155. doi:10.1016/j.progpolymsci.2008.10.002.

[5] J.M. Raquez, Y. Habibi, M. Murariu, P. Dubois, Polylactide (PLA)-based nanocomposites, Prog. Polym. Sci. 38 (2013) 1504-1542. doi:10.1016/j.progpolymsci.2013.05.014.

[6] V. Ojijo, S. Sinha Ray, Processing strategies in bionanocomposites, Prog. Polym. Sci. 38 (2013) 1543-1589. doi:10.1016/j.progpolymsci.2013.05.011.

[7] R.J. Moon, A. Martini, J. Nairn, J. Simonsen, J. Youngblood, Cellulose nanomaterials review: structure, properties and nanocomposites, 2011. doi:10.1039/c0cs00108b.

[8] J. Dlouhá, L. Suryanegara, H. Yano, Cellulose nanofibre-poly(lactic acid) microcellular foams exhibiting high tensile toughness, React. Funct. Polym. 85 (2014) 201-207. doi:10.1016/j.reactfunctpolym.2014.07.016.

[9] S. Deville, Ice-templating, freeze casting: Beyond materials processing, J. Mater. Res. 28 (2013) 2202-2219. doi:10.1557/jmr.2013.105.

[10] C. Adu, L. Berglund, K. Oksman, S.J. Eichhorn, M. Jolly, C. Zhu, Properties of cellulose nanofibre networks prepared from never-dried and dried paper mill sludge, J. Clean. Prod. 197 (2018) 765-771. doi:10.1016/j.jclepro.2018.06.263.

[11] S. Gupta, F. Martoïa, L. Orgéas, P. Dumont, Ice-Templated Porous NanocelluloseBased Materials: Current Progress and Opportunities for Materials Engineering, Appl. Sci. 8 (2018) 2463. doi:10.3390/app8122463.

[12] D. Liu, Z. Ma, Z. Wang, H. Tian, M. Gu, Biodegradable Poly ( vinyl alcohol ) Foams Supported by Cellulose Nano fi brils : Processing, Structure, and Properties, Langmuir. (2014).

[13] Y. Zhou, S. Fu, Y. Pu, S. Pan, A.J. Ragauskas, Preparation of aligned porous chitin nanowhisker foams by directional freeze-casting technique, Carbohydr. Polym. 112 (2014) 277-283. doi:10.1016/j.carbpol.2014.05.062.

[14] A. Liu, L. Medina, L.A. Berglund, High-Strength Nanocomposite Aerogels of Ternary Composition: Poly(vinyl alcohol), Clay, and Cellulose Nanofibrils, ACS Appl. Mater. Interfaces. (2017) acsami.6b15561. doi:10.1021/acsami.6b15561. 
[15] S. Mueller, J. Sapkota, A. Nicharat, T. Zimmermann, P. Tingaut, C. Weder, E.J. Foster, Influence of the nanofiber dimensions on the properties of nanocellulose/poly(vinyl alcohol) aerogels, J. Appl. Polym. Sci. 132 (2015) 1-13. doi:10.1002/app.41740.

[16] M. Ghanadpour, B. Wicklein, F. Carosio, L. Wågberg, All-natural and highly flameresistant freeze-cast foams based on phosphorylated cellulose nanofibrils, Nanoscale. 10 (2018) 4085-4095. doi:10.1039/c7nr09243a.

[17] B. Wicklein, A. Kocjan, G. Salazar-Alvarez, F. Carosio, G. Camino, M. Antonietti, L. Bergström, Thermally insulating and fire-retardant lightweight anisotropic foams based on nanocellulose and graphene oxide, Nat. Nanotechnol. 10 (2015) 277-283. doi:10.1038/nnano.2014.248.

[18] R. Dash, Y. Li, A.J. Ragauskas, Cellulose nanowhisker foams by freeze casting, Carbohydr. Polym. 88 (2012) 789-792. doi:10.1016/j.carbpol.2011.12.035.

[19] M.F. Gibson, L. J. Ashby, Cellular Solids: Structure and Properties, Cambridge university press, Cambridge, UK, 1997. doi:https://doi.org/10.1017/CBO9781139878326.005.

[20] P. Munier, K. Gordeyeva, L. Bergström, A.B. Fall, Directional Freezing of Nanocellulose Dispersions Aligns the Rod-Like Particles and Produces Low-Density and Robust Particle Networks, Biomacromolecules. 17 (2016) 1875-1881. doi:10.1021/acs.biomac.6b00304.

[21] A.J. Svagan, L.A. Berglund, P. Jensen, Cellulose nanocomposite biopolymer foamhierarchical structure effects on energy absorption, ACS Appl. Mater. Interfaces. 3 (2011) 1411-1417. doi:10.1021/am200183u.

[22] V. Mittal, Polymer nanocomposite foams, Polym. Nanocomposite Foam. (2013) 1241. doi:10.1201/b15572.

[23] J. Han, Y. Yue, Q. Wu, C. Huang, H. Pan, X. Zhan, C. Mei, X. Xu, Effects of nanocellulose on the structure and properties of poly(vinyl alcohol)-borax hybrid foams, Cellulose. 24 (2017) 4433-4448. doi:10.1007/s10570-017-1409-4.

[24] G. Newaz, M. Mayeed, A. Rasul, Characterization of balsa wood mechanical properties required for continuum damage mechanics analysis, Proc. Inst. Mech. Eng. Part L J. Mater. Des. Appl. 230 (2016) 206-218. doi:10.1177/1464420714564711.

[25] British Standards Institution BSI, BS 3837-1:2004 Expanded polystyrene boards Part 1: Boards and blocks manufactured from expandable beads - Requirements and test methods, 3 (2004).

[26] Jablite, Jabfloor 100 technical specification, (2019). https://www.jablite.co.uk/application/jabfloor-flooring-insulation-hp/ (accessed March 20, 2019).

[27] Dow, ETHAFOAM 180 product information, (2017). http://www.qualityfoam.com/docs/ethafoam-180.pdf. 


\title{
Structural packaging foams prepared by uni-directional freezing of paper sludge cellulose nanofibres and poly (vinyl alcohol)
}

\author{
Adu, Cynthia
}

Elsevier

Adu C, Rahatekar S, Filby J, et al., (2019) Structural packaging foams prepared by

uni-directional freezing of paper sludge cellulose nanofibres and poly (vinyl alcohol). Materials

Letters, Volume 253, October 2019, pp. 242-245

https://doi.org/10.1016/j.matlet.2019.06.050

Downloaded from Cranfield Library Services E-Repository 